\title{
LA CONCENTRACIÓN PARCELARIA Y SUS FASES
}

\author{
Ángel SÁNCHEZ HERNÁNDEZ
}

PROFESOR TITULAR E.U. DE DERECHO CIVIL

UNIVERSIDAD DE LA RIOJA

$\mathrm{s}$ u m a r i o

I. Inicio del procedimiento. 2. Decreto de concentración parcelaria. 3. La Comisión Loca de Concentración Parcelaria. 4. Bases de la concentración. 5. Proyectos de concentración parcelaria. 6. Acuerdo de concentración parcelaria. 7. Plan de obras y mejoras territoriales. Replanteo de las fincas de reemplazo. 8. Replanteo y amojonamiento de las fincas de reemplazo. - Bibliografía.

En España, la Concentración Parcelaria, se inicia con la promulgación de la Ley de 20 de diciembre de I952, encomendándose las tareas de desarrollo y ejecución de la misma al Servicio de Concentración Parcelaria, luego Servicio de Concentración Parcelaria y Ordenación Rural, fusionándose más tarde dicho servicio con el Instituto Nacional de Colonización para constituir el Instituto Nacional de Reforma y Desarrollo Agrario (IRYDA).

En la década de los setenta, la Concentración Parcelaria se realiza en base a lo dispuesto en la Ley de Reforma y Desarrollo Agrario aprobada por Decreto II8/1973 de I2 de enero.

Con la Constitución Española de I978 y el nuevo modelo territorial del Estado, las tareas de Concentración Parcelaria han sido transferidas a las Comunidades Autónomas, algunas de las cuales han elaborado su propia Ley de Concentración Parcelaria -vg. Ley 4/I990, de 23 de marzo de Cantabria, Ley I4/I990, de 28 de noviembre de Castilla y León, modificada por la Ley 4/2005 de 23 de mayo y la Ley Io/I985 de I4 de agosto de Galicia, modificada por la Ley I2/200I, de Io de septiembre-. Sin embargo, todavía hoy en la mayoría de las Comunidades Autónomas, entre ellas La Rioja, la Concentración Parcelaria se realiza en base a lo dispuesto en la Ley de Reforma y Desarrollo Agrario aprobada por Decreto II8/I973 de I2 de enero. 
Seguidamente expondré las sucesivas fases del procedimiento de Concentración Parcelaria, en base a la legislación estatal contenida en el Título VI, del Libro $3^{\circ}$ de la Ley de Reforma y Desarrollo Agrario aprobada por Decreto II8/1973 de I2 de enero -en adelante LRYDA-.

I. Inicio del procedimiento.

El expediente de concentración parcelaria puede promoverse:

a) de oficio si la disposición parcelaria en una zona es grave -tiene acusados caracteres de gravedad-. Por tanto, por razones de utilidad pública, se pude llevar a cabo la concentración parcelaria de oficio,

b) a petición de la mayoría de los propietarios de la zona,

c) a petición de un número cualquiera de los propietarios de la zona a quienes pertenezcan más de las tres cuartas partes de la superficie a concentrar, porcentaje que quedará reducido al cincuenta por ciento, cuando los propietarios que lo soliciten se comprometan a explotar sus tierras de manera colectiva -artículos I80 y I8I de la LRYDA-.

A continuación, en los dos últimos supuestos, el Ayuntamiento al que corresponda el término municipal en cuyo territorio se realizará la concentración parcelaria, tramitará la solicitud, avalando las firmas presentadas por los propietarios solicitantes.

2. Decreto de concentración parcelaria.

Recibida la solicitud, el organismo competente de la Comunidad Autónoma, tramitará el expediente una vez que se hayan emitido los informes técnicos pertinentes. Si éstos son favorables, se propondrá al Consejo de Gobierno de la Comunidad Autónoma que se Decrete la concentración Parcelaria para la zona -artículo I7I LRYDA-.

El Decreto de concentración parcelaria, se publicará en el Boletín Oficial de la Comunidad Autónoma y contendrá los siguientes pronunciamientos -artículos I7I.3 y I72 de la LRYDA-:

a) declaración de utilidad pública y de urgente ejecución de la concentración parcelaria de la zona de que se trate.

b) Determinación, provisional, del perímetro de la zona a concentrar, con la salvedad expresa de que dicho perímetro podrá ser modificado en virtud de las inclusiones, rectificaciones o exclusiones que se acuerden.

Acordada la realización de la Concentración Parcelaria, ésta será obligatoria para todos los propietarios de parcelas afectadas y para los titulares de derechos reales y situaciones jurídicas existentes sobre ellos. 
Desde la publicación del Decreto, tanto los propietarios como los cultivadores están obligados a :

$\mathrm{I}^{\mathrm{o}}$. cuidar de las parcelas sujetas a concentración parcelaria

$2^{\circ}$. cultivarlas al uso y costumbre de buen labrador.

No pueden destruir obras, esquilmar la tierra, ni realizar ningún acto que disminuya el valor de tales parcelas. Si lo hicieren, incurrirían en multa en cuantía doble a la disminución del valor que hubiese experimentado la aportación.

Si se realizase en las parcelas sujetas a Concentración Parcelaria cualquier tipo de obra o mejora, no serán tenidas en cuenta al efecto de clasificar y valorar las tierras salvo que la realización de las mismas cuente con autorización administrativa.

3. La Comisión Local de Concentración Parcelaria.

Publicado el Decreto de Concentración Parcelaria, se constituirá la Comisión Local de Concentración Parcelaria que estudiará las Bases de la Concentración y propondrá a la Consejería competente su aprobación.

La Comisión Local estará presidida, con voto de calidad, por el Juez de Primera Instancia de la jurisdicción de la zona, y formarán parte de ella:

$\mathrm{I}^{\mathrm{o}}$. como vicepresidente, un funcionario -jefe de servicio- de la consejería competente

$2^{\circ}$. y como vocales: el registrador de la propiedad de la zona, el notario de la zona, un ingeniero agrónomo de la Consejería competente, el alcalde -o presidente de la Entidad Local correspondiente-, un representante de la Cámara Agraria y tres representantes de los agricultores de la zona elegidos en asamblea entre los participantes en la Concentración Parcelaria: uno entre los mayores aportantes de bienes, otro entre los medianos y el tercero entre los menores.

En la misma asamblea en que son elegidos los tres representantes de los agricultores de la zona, se designarán a los seis agricultores que, sin formar parte de la Comisión Local, auxiliaran a esa en los trabajos de calificación de tierras, como Junta de Clasificación.

Como secretario, actuará un funcionario de la Consejería competente, que tenga la condición de letrado.

\section{Bases de la concentración.}

La Ley de Reforma y Desarrollo Agrario no las define, limitándose a regularlas. Constituyen la pieza fundamental de la propia Concentración Parcelaria. Precisamente los 
trabajos de la misma, se iniciarán con la preparación de las «Bases» y antes de exponerlas públicamente, se realizarán los siguientes trabajos:

A. Obtención de la cartografía de partida. Se preparan unos planos parcelarios divididos por polígonos en los que quedan reflejadas las correspondientes parcelas con su numeración correspondiente, infraestructuras, accidentes naturales, toponimia,...

B. Notificaciones. La Consejería competente de la Comunidad Autónoma comunicará al registrador de la propiedad correspondiente y al notario del distrito, por una parte los términos municipales afectados por el decreto de Concentración Parcelaria, así como la determinación del perímetro a concentrar en cada zona.

Se comunicará la zona afectada por la Concentración Parcelaria al Ministerio Fiscal para que asuma la defensa de las personas cuyos intereses estén a su cargo.

Se enviarán notificaciones a distintos organismos públicos con competencias en obras públicas, transportes, carreteras, medio natural, así como a empresas que prestan servicios públicos -vg. electricidad, gas, telefonía- y a las entidades financieras - vg. bancos y Confederación Española de Cajas de Ahorro-, para que, los primeros, manifiesten si existe alguna superficie de la zona a concentrar que sea de dominio público y las segundas, para que manifiesten si alguna de las superficies afectadas se halla gravada con hipotecas, cargas o servidumbres de cualquier tipo.

C. Clasificación de tierras. Sobre los planos parcelarios, en un trabajo de campo, se van dibujando las líneas que separan las distintas clases de tierras que han sido fijadas para la zona en función de su valor agronómico -generalmente de primera a décima-. Este trabajo lo realizan los técnicos de la Consejería competente, acompañados por la Junta de Clasificación elegida por los propietarios afectados. A la vez, se van reflejando en los planos las zonas a excluir de la Concentración Parcelaria bien sea por su topografía accidentada, bien por ser superficies de dominio público, ...

También se fijan los valores de los coeficientes que han de servir para realizar, si procede, las compensaciones entre los distintas clases de tierras, así como las parcelas tipo para cada una de esas clases. Estas parcelas servirán de modelo a los propietarios para comparar con la clasificación dada a sus parcelas.

Las Bases antes de ser definitivas, son provisionales. Para fijar las BASES PROVISIONALES, han de realizarse, simultáneamente o alternativamente, los trabajos de «investigación de la propiedad» $\mathrm{y}$ «clasificación de tierras».

En cuanto se refiere a la «investigación de la propiedad», determinará los propietarios de las tierras, la condición de tenencia o posesión, la de los derechos reales y de las situaciones jurídicas que tengan por base física las parcelas de procedencia. En suma, se trata de determinar la situación jurídica de las parcelas comprendidas en el perímetro de la zona a concentrar, teniendo en cuenta la titularidad que presenten los interesados, los derechos inscritos en el Registro de la Propiedad e incluso las situaciones posesorias . En este periodo, los participantes presentarán, si existiesen, los títulos escritos en que se funde 
su derecho, declarando, en todo caso, los gravámenes o situaciones jurídicas que conozcan y afecten a sus parcelas o derechos. Si los poseedores de las parcelas afectadas por la Concentración Parcelaria careciesen de título escrito de propiedad, tal carencia no obstaculizará las operaciones de Concentración Parcelaria.

Si existiesen discrepancias entre el Registro de la Propiedad y la realidad extrarregistral, prevalecerá ésta sobre aquél. La posesión material en concepto de dueño desplaza siempre a la posesión tabular, es decir, las situaciones posesorias existentes sobre las fincas son respetadas: al poseedor real en concepto de dueño se le presume propietario antes que al titular registral. Ello no implica que quede desamparado el titular registral, puesto que el artículo I93 de la Ley de Reforma y Desarrollo Agrario, establece en su favor pronunciamientos para la interpretación de los asientos registrales contradictorios y estudio de los documentos que acrediten la titularidad de los bienes, dejando constancia en el expediente de cuantas situaciones jurídicas deriven de estas circunstancias, mientras se resuelven judicialmente o extrajudicialmente.

Para la clasificación de las tierras, se valorarán objetivamente los diferentes tipos de tierra partiendo de unas parcelas modelo previamente fijadas por la Junta de clasificación. Estamos ante una clasificación fundamental puesto que se está efectuando una valoración comparativa exacta y precisa de todos los terrenos de la zona, con la posibilidad de intercambio de calidades de tierra en el momento de situar la fincas de reemplazo. La clasificación comprende las siguientes fases: $\mathrm{I}^{\circ}-\mathrm{El}$ reconocimiento de las características generales de la zona; $2^{\circ}-$ la fijación del número de clases que se van a emplear en la clasificación, dependiendo de los tipos de cultivo; $3^{\circ}$-elección de las parcelas tipo de cada clase para compararlas con el resto de parcelas de la zona; $4^{\circ}$-la clasificación propiamente dicha de todas y cada una de las parcelas.

Si en la zona a concentrar existen unos peculiares tipos de cultivo -viñas, olivos, manzanos,...-, será conveniente el incluir alguna clase que valore estos cultivos. En todo caso, en el momento de la clasificación ha de tenerse en cuenta los siguientes extremos: a el aspecto general de la parcela, b-la profundidad del suelo y si aflora roca o no; c-la situación de la parcela -zona llana, valle, collado...-; d-orientación -norte o sur-; eorografía -uniforme u ondulada-; f-topografía - existencia de pendientes,...-; g-distancia al núcleo de población; h-productividad de la finca. Todos estos aspectos cuenta con una escala de valores relativa, existiendo uno o más puntos que destaquen sobre los otros, siendo la Junta de Clasificación la que valora el conjunto de las características de la parcela, manteniendo el mismo criterio comparativo. Por último, se reflejará también otras circunstancias que afecten a la parcela, como por ejemplo la existencia de fuentes, edificaciones, construcciones, servidumbres eléctricas, accidentes del terreno, etc...

Una vez acabada la «investigación de la propiedad» y la «clasificación de las tierras», se procede a la delimitación de la superficie de cada parcela en su totalidad y por clases, así como a plasmar todos los datos de campo en los planos originales y a confeccionar las fichas parcelarias y los boletines individuales de la propiedad -impreso del que se entregará una copia a cada propietario, donde se reflejan sus circunstancias personales, polígono, número de parcelas, superficie y clase de tierras, tipo de explotación, cargas y gravámenes y cualquier otra observación que afecte a la titularidad o naturaleza jurídica.

Reunidos todos esos datos que permiten establecer con carácter provisional las BASES de la concentración, se realizará una encuesta -publicación y periodo de exposición pública- de las bases provisionales para que los afectados formulen las observaciones que estimen pertinentes. Se atenderán en este periodo todas las alegaciones pertinentes, tanto a la clasificación y superficie, como a la titularidad de las parcelas. Esta encuesta sobre las BASES se abre mediante avisos insertos en el tablón de anuncios del Ayuntamiento, 
haciendo público, que en el plazo de treinta días hábiles, estarán expuestos en el mismo los documentos correspondientes para que los interesados puedan formular las observaciones -verbales o escritas- que estimen oportunas.

Una vez recogidas y estudiadas todas las alegaciones y previas las comprobaciones y rectificaciones pertinentes, como consecuencia de las alegaciones presentadas, la Comisión Local, elaborará y someterá al órgano competente de la Consejería correspondiente, las BASES DEFINITIVAS siguientes:

Primero: El perímetro de la zona a concentrar, con la relación de parcelas cuya exclusión se propone. Téngase presente que las superficies de dominio público y los bienes comunales, están exceptuados de la Concentración Parcelaria, salvo que se solicite su inclusión.

Segundo: La clasificación de tierras y fijación previa de los respectivos coeficientes que han de servir de base para llevar a cabo compensaciones, cuando resulten necesarios.

Tercero: Declaración de dominio de las parcelas a favor de quienes las posean en concepto de dueño, y determinación de la superficie perteneciente a cada uno y de la clasificación que corresponde a dicha superficie.

Cuarto: La relación de gravámenes y otras situaciones jurídicas que hayan quedado determinadas en el periodo de investigación.

Una vez APROBADAS LAS BASES por el órgano que corresponda, se publicarán por éste mediante aviso inserto una sola vez el correspondiente Boletín Oficial y por tres días en el tablón de anuncios del Ayuntamiento y en el de la Entidad Local correspondiente, advirtiendo que la documentos estarán expuestos durante treinta días hábiles, desde la inserción del último aviso, para que los afectados puedan entablar recurso ordinario ante el organismo pertinente. Tras la exposición publica de las BASES DEFINITIVAS y una vez resueltos los recursos presentados a dicha fase, se entenderá que las bases definitivas son firmes.

Hasta este momento en que las BASES DEFINITIVAS son firmes, se han determinado con el mayor detalle posible el perímetro de la zona a concentrar, el número de parcelas que posee cada propietario, la superficie y el valor que tienen cada una , así como las cargas que soportan. Todos los datos y aportaciones de cada propietario se recogen en los Boletines Individuales de la Propiedad.

\section{Proyecto de concentración parcelaria.}

Antes del inicio del Proyecto de Concentración Parcelaria es necesario realizar dos tareas fundamentales para el diseño de las nuevas fincas de reemplazo:

Primero, poner a disposición de los propietarios un impreso encuesta para que manifiesten -si lo estiman oportuno-, sus preferencias sobre: alos lotes de reemplazo que desea le sean adjudicados; b-sobre qué parcela o zona; c-si hay alguna parcela que desee conservar por algún motivo; d-al lado de que otro propietario desearía le fueran situadas sus nuevas fincas; e-y por último, cualquier otra observación que estime de interés. 
La realización de esta encuesta a los propietarios sobre la ubicación de las fincas de reemplazo y las razones que tienen para ello, no implica obligatoriedad , compromiso, ni es condicionante alguno para la Administración competente, sirviendo únicamente de orientación a los técnicos para encajar las nuevas fincas sobre el terreno.

Segundo, realizar un estudio de las vías de comunicación de la zona a concentrar, que se plasmará en el correspondiente proyecto de obras. Uno de los objetivos de la Concentración Parcelaria es dar a las nuevas fincas acceso directo a las vías de comunicación, para lo cual se estudiarán las vías de comunicación, las vías de acceso a las futuras fincas de reemplazo y la posibilidad de mejora o ampliación de las vías ya existentes.

Se trata de la definición y trazado de los futuros caminos que han de servir para dar acceso a las nuevas fincas, así como de los desagües necesarios para el saneamiento y drenaje de las zonas que tengan problemas de encharcamiento o de aguas torrenciales.

Esta red de caminos y desagües, junto con otros accidentes naturales, generan los espacios en los que se irán ubicando las fincas de reemplazo. La superficie ocupada por las obras de caminos y desagües se deducen en la misma proporción a todos los participantes en la concentración. En la realización de estos trabajos se intentará ser lo más respetuoso posible con el medio natural, evitando afectar con los caminos y las obras a zonas especialmente sensibles como masas arbóreas, bosques, etc...

Si ya a la hora de delimitar las zonas a concentrar se excluyen del proceso aquellos que tengan interés medio ambiental o sociocultural, laderas en las que la Concentración Parcelaria favorecería la erosión, ....ahora al diseñar las nuevas fincas se procurará mantener como linde natural los ribazos importantes con lo que se evita su desaparición, se respeta la flora y la fauna existente.

Para el proyecto de caminos y desagües de la zona, se realizarán los trabajos de topografía necesarios para calcular los movimientos de tierras, se definirán rozantes, las obras de fábrica..., ajustándose todo ello a las trazas definidas en los planos del Proyecto de Concentración.

Finalizados los trabajos de encuesta y diseño de las obras, se van adjudicando las nuevas fincas de la manera más equitativa posible conforme prevea el proyecto de concentración, el cual constará de:

Primero: Un plano que reflejará la nueva distribución de la propiedad.

Segundo: Una relación de propietarios en la que, con referencia al Plano, se indique las fincas que en un principio se asignan a cada uno de ellos.

Tercero: Una relación de servidumbres prediales que hayan de establecerse según las conveniencias de la nueva ordenación de la propiedad.

Todo ello requiere unos cálculos previos al proyecto que comprende:

a) La determinación de las aportaciones de cada propietario. 
b) El cálculo de la superficie y valor total a distribuir y la determinación, en función de los datos anteriores, del coeficiente de reducción.

Con carácter general, ha de tenerse en cuenta las circunstancias siguientes:

$\mathrm{I}^{\circ}$. Se procurará realizar la compensación por clases de tierra, entre clases próximas de forma que la superficie total de cultivo no difiera sustancialmente de la total aportada.

$2^{\circ}$. Se promediara el emplazamiento de las nuevas fincas en relación con su distancia al casco urbano, con la distancia media a la que estaban situadas las parcelas aportadas.

$3^{\circ}$. Debe evitarse la compensación de tierras en sectores de características diferentes.

$4^{\circ}$. Se procurará que la forma de las fincas sea rectangular o, al menos que los linderos de mayor longitud sean paralelos y que su mayor dimensión sea de tres a seis veces la menor.

$5^{\circ}$. Se evitarán las adjudicaciones de fincas muy alargadas o de formas irregulares: triangulares, con entrantes,...

$6^{\circ}$. A los propietarios residentes en términos colindantes se les procurará hacer adjudicaciones lo más próximas posibles a dichos términos, dando a esta circunstancia primacía sobre las demás.

$7^{\circ}$. Las superficies incluidas en concentración cuyo propietario es «desconocido» formarán una unidad, constituyéndose un lote de reemplazo equivalente al conjunto de las parcelas cuyo propietario es desconocido.

$8^{\circ}$. Las servidumbres deben establecerse en el proyecto de concentración de tal forma que sean viables en todo su recorrido, procurando no dividir fincas de reemplazo con ellas y tratando además de que su longitud sea la menor posible.

$9^{\circ}$. Se procurará adjudicar contiguas las fincas integradas en una misma explotación, auque pertenezcan a distintos propietarios, a efectos de conseguir la máxima reducción posible de fincas a efectos de cultivo.

I0 ${ }^{\circ}$. Un caso especial es el de aquellos propietarios que se han agrupado para el cultivo en común de sus tierras -artículo 204 de la Ley de Reforma y Desarrollo Agrario-. Siempre que se acredite de forma legal, antes de que sean firmes las BASES, la constitución de una asociación para la explotación de la tierra, se redactará el proyecto de Concentración de tal forma que queden contiguas la mayor parte de las fincas de reemplazo que se adjudiquen a los componentes de la asociación.

Pues bien, una vez confeccionado el proyecto de concentración se realizará una encuesta -consistente en la publicación de dicho proyecto para que todos puedan formular las observaciones que estimen oportunas-, que se abrirá mediante avisos tres días insertos en el tablón de anuncios del Ayuntamiento o de la Entidad Local que corresponda, haciendo público que durante treinta días hábiles - prorrogables- a contar desde la última inserción, 
estarán expuestos en el Ayuntamiento los documentos correspondientes para que los interesados puedan formular las observaciones -verbales o escritas- que estimen oportunas.

\section{Acuerdo de concentración parcelaria.}

Terminada la encuesta, se determinará la nueva ordenación de la propiedad, introduciendo en el proyecto las modificaciones que de la misma se deriven -como consecuencia de las alegaciones habidas al mismo- y determinando las fincas de reemplazo que han de quedar afectadas por los gravámenes y situaciones jurídicas que recaían sobre las parcelas de procedencia. El acuerdo de concentración se ajustará estrictamente a las «Bases Definitivas», en el perímetro, en el valor de las parcelas aportadas al proceso y en la relación de gravámenes y otras situaciones jurídicas de aplicación.

Aprobado el acuerdo de concentración, se hace público mediante un aviso inserto en el Boletín Oficial correspondiente y por tres días en el tablón de anuncios del Ayuntamiento -o en el de la Entidad Local que corresponda-, advirtiendo que los documentos estarán expuestos durante treinta días hábiles, a contar desde la inserción del último aviso, y que dentro de ese plazo, los interesados pueden interponer recurso de alzada ante el órgano correspondiente, que los resolverá.

7. Plan de obras y mejoras territoriales. Replanteo de las fincas de reemplazo.

El plan de obras redactado y aprobado por disposición legal, se ejecutará con los correspondientes proyectos de obras: realización de explotaciones de la red de caminos, excavaciones de desagües, construcción de obras de fábrica, accesos a fincas y todo ello como requisito indispensable para el replanteo de las nuevas fincas (En ocasiones, la ejecución de las obras es un proceso simultáneo al amojonamiento de las nuevas fincas).

8. Replanteo y amojonamiento de las fincas de reemplazo.

Terminada la publicación del acuerdo de concentración y tras la resolución de los recursos presentados, una vez firme el acuerdo, se procederá al replanteo de las fincas de reemplazo -amojonamiento-, colocándose mojones que delimitarán en el campo las fincas de reemplazo, caminos de servicio, zonas excluidas, ... Posteriormente, se abrirá un periodo de «encuesta» que servirá para realizar las correcciones pertinentes.

9. Toma de posesión de las fincas de reemplazo.

Terminada la publicación del acuerdo de concentración parcelaria siempre que el número de recursos no exceda del cuatro por ciento de propietarios, se podrá dar la posesión provisional de las nuevas fincas, sin perjuicio de las rectificaciones que procedan como consecuencia de los recursos que prosperen. 
Dentro de los treinta días siguientes a la fecha en que las fincas de reemplazo sean puestas a disposición de los participantes para que tomen posesión de ellas, los interesados podrán reclamar, acompañando dictamen pericial, sobre diferencias superiores al dos por ciento entre la cabida de las nuevas fincas y la que conste en el título o en el expediente de concentración parcelaria. Si la reclamación fuera estimada, se modificará el acuerdo compensando al reclamante con cargo a la masa común.

Una vez resueltos los recursos planteados al acuerdo de concentración y las alegaciones habidas al amojonamiento de nuevas fincas, se procede por la Administración a dar firmeza al acuerdo de concentración.

Una vez firmes las Bases definitivas así como el acuerdo de concentración parcelaria, los interesados que hubieren presentado recurso de alzada ante el órgano competente y su resolución no fuese favorable a sus intereses, podrán interponer recurso contencioso-administrativo.

Io. Acta de reorganización de la propiedad.

En primer lugar, se procederá a la aprobación del acta de reorganización de la propiedad. Así, firme el acuerdo de concentración, se extenderá y autorizará el acta de reorganización de la propiedad, donde se relacionarán y describirán las fincas resultantes de la concentración parcelaria -fincas de reemplazo-, con las circunstancias necesarias para la inscripción se las mismas en el Registro de la Propiedad. Se consignarán también en este documento los derechos distintos del dominio existentes sobre las antiguas parcelas parcelas de procedencia-, que impliquen posesión de las mismas y la finca de reemplazo sobre la que hayan de recaer tales los derechos, relacionándose así mismo los demás derechos reales y situaciones jurídicas que hayan podido ser determinadas en el periodo de investigación y la finca sobre la que hayan de establecerse.

En según lugar, se procederá a la protocolización. Se remitirá un plano general de la zona concentrada autorizado por la Administración junto con el Acta de reorganización de la propiedad, para su protocolización por el notario. El Acta susodicha será protocolizada por el notario que haya formado parte de la Comisión Local o por el que lo haya sustituido, y las copias parciales que expida, servirán de título de dominio a los participantes en la Concentración Parcelaria, correspondiendo a la Administración promover la inscripción de dichos títulos en el Registro de la Propiedad y posterior entrega a los interesados de los títulos de propiedad de la fincas.

La nueva ordenación de la propiedad resultante de la concentración será reflejada en el Catastro de Rústica, remitiéndose al mismo una copia de los planos y listado de la Concentración Parcelaria, al que quedarán oficialmente incorporados. El Catastro de Rústica adaptará a la nueva situación los planos del municipio o municipios afectados por la Concentración Parcelaria y remitirá al Registro de la Propiedad respectivo los nuevos planos ya rectificados.

Las «tierras sobrantes»-masas comunes- durante un plazo de tres años, contados desde que el acuerdo de Concentración Parcelaria sea firme, podrán ser utilizados para subsanar los errores que se adviertan, cuando sea procedente. Transcurridos dichos tres años, las tierras se cederán a los Ayuntamientos correspondientes, con la condición de que destinen los ingresos obtenidos de su explotación al mantenimiento de la red de caminos y desagües.

Redur 4 / 2006 
Bibliografía.

AgUNDEZ FERNÁNDEZ, A., «Procedimiento de concentración parcelaria y régimen impugnativo de sus acuerdos», Revista de Estudios Agro-sociales, abril-junio de I966.

BERMEJO LATRE, J.L., «Nuevas perspectivas de la concentración parcelaria», en Estudios de Derecho Agrario, VII Congreso Nacional de Derecho Agrario, Valencia I999, p. 493 y SS.

LORENZO MERINO, F. «La Ley de concentración parcelaria para Galicia de I4 de agosto de I985. Principios de aspectos definidores», La Ley, $\mathrm{n}^{\circ} 3$ de I986, p. 870 y ss.

SANZ JARQUE, J.J.,

- Legislación y procedimiento de concentración parcelaria, Madrid, I963.

- «La experiencia Europea en concentración parcelaria», Revista Crítica de Derecho Inmobiliario, julio-agosto de ig64, $\mathrm{n}^{\circ}$ 434-435, pp. 446 a 484 .

- «Normativa de la concentración parcelaria y de la ordenación rural. Reforma de estructuras agrarias», Revista de Derecho Español y Americano, $\mathrm{n}^{\circ}$ 5, julioseptiembre I965.

TEllez De Peralta, J.D., «Notas sobre la naturaleza Jurídica e la concentración parcelaria en la Ley de reforma agraria andaluza», en Derecho Agrario Autonómico, Universidad de Oviedo, Oviedo, I99I, pp. 45I y ss.

VATTIER FUENZALIDA, C., «Reforma de estructuras y concentración parcelaria», Revista de Derecho Agrario y Alimentario, Octubre I986-marzo I987, pp. 21 y ss. 